\section{Is a low insulin response to intravenous glucose an marker of Type 1 (insulin-dependent) diabetes?}

Dear Sir,

Recently B. Vialettes et al. published the results of a study to determine the value of low acute insulin response to intravenous glucose as a marker of early stages of Type 1 (insulin-dependent) diabetes mellitus [1].

In their article the authors raise the question, whether low acute insulin response is a reliable marker of pre Type 1 diabetes in young patients. In their conclusion they state, that a low acute insulin response to glucose is a sensitive but not specific marker of early stages of Type 1 diabetes. They based their results on a population of 39 individuals with mild or transient hyperglycaemia with fasting blood-glucose levels between 7.7 and $10.0 \mathrm{mmol} / 1$ by two separate measurements. According to WHO criteria they can thus be classified as diabetic patients [2]. The population was followed for three years. They state that at the end of this period the patients were insulin-dependent. This insulin-dependency however, is not defined and seems to be nothing more than insulin treated.

In a group of 150 first degree relatives of Type 1 diabetic patients only two persons became diabetic. Obviously this number is too low to make a reliable estimate of sensitivity and specificity.

\section{Response from the authors}

Dear Sir,

We are only partly in agreement with Dr. Razenberg's statement. We readily admit that the small number of diabetic subjects appearing in our cohort of relatives of Type 1 (insulin-dependent) diabetic patients during the 3 years does not allow us to assert that low acute insulin response to glucose (LAIR) is a sensitive marker of evolution to Type 1 diabetes in the near future [1]. However, if one pools our two cases to the four reported by Ganda [2] and the seven by Chase [3], it would appear that LAIR is a common feature of pre-Type 1 diabetes. With regards to the poor specificity of LAIR, we do think that our data allows this conclusion. Prevalence of LAIR is almost twice that of the theoretical risk of diabetes in this population of relatives of Type 1 diabetic patients. Obviously not all the subjects with LAIR will become diabetic in the future. Finally, our paper stresses that some relatives of Type 2 diabetic patients may also exhibit the same anomaly of the insulin response.

Yours sincerely,

B. Vialettes, C.Mattai-Zevaco and Ph. Vague
The conclusion is thus only valid in diabetic patients, who may or may not be suffering from slow Type 1 diabetes. For the relatives of Type 1 diabetic patients no conclusion can be drawn at all.

Yours sincerely, P.P.A. Razenberg

\section{References}

1. Vialettes B, Mattei-Zevaco C, Badier C, Ramahandridona G, Lassmann-Vague V, Vague $P(1988)$ Low acute insulin response to intravenous glucose. A sensitive but non-specific marker of early stages of Type 1 (insulin-dependent) diabetes. Diabetologia 31: 592-596

2. WHO expett committee on diabetes mellitus. Second report. WHO Tech Rep Ser (1985) 727

Dr. P.P.A. Razenberg

Kliniek inwendige geneeskunde

Academisch Ziekenhuis

Vrije Universiteit

Postbus 7057

NL-1007 MB Amsterdam

The Netherlands

\section{References}

1. Vialettes $B$, Mattei-Zevaco $C$, Badier $C$, Ramahandridona $G$, Lassmann-Vague $V$, Vague $P(1988)$ Low acute insulin response to in travenous glucose. A sensitive but non-specific marker of early stages of Type 1 (insulin-dependent) diabetes. Diabetologia 31: $592-596$

2. Ganda OMP, Srikanta S, Brink SI, Morris MA, Gleason RE, Soeldner JS, Eisenbarth GS (1984) Differential sensitivity of B-cell secretagogues in "early" type 1 diabetes mellitus. Diabetes 33: 516-521

3. Chase HP, Voss MA, Butler-Simon N, Hoops S, O'Brien D, Dobersen MJ (1987) Diagnosis of pre-type 1 diabetes. J Pediatr 3: $807-812$

Dr. B. Vialettes

Departement de Diabetologie

Hopital Universitaire Michel Levy

$84 \mathrm{a}$, rue de Lodi

F-13006 Marseille

France

\section{Effect of $\alpha_{\mathrm{a}}$-adrenoceptor antagonist on platelet activation during insulin-induced hypoglycaemia in Type 2 (non-insulin-dependent) diabetes mellitus}

Dear Sir,

Takeda et al. [1] have established that the platelet hyperaggregability occurring during acute hypoglycaemia is mediated by elevated plasma levels of adrenaline. A few additional comments may be of interest.
The conclusions of Takeda et al. [1] are supported by the finding that the elevated plasma concentrations of ACTH, cortisol, growth hormone and prolactin that occur during acute hypoglycaemia are unlikely to activate platelets [2-4].

Elevated plasma adrenaline concentrations may also exert potentially adverse effects other than platelet activation. For example, this catecholamine induces a hypokalaemia (probably mediated by beta adrenoceptors) which may in turn increase the risk of cardiac arrhythmia [5]. Another catecholamine-dependent process which occurs during hypoglycaemia, the elevation of plasma coagulation factor VIII: RAg concentration, also appears to be at least partially dependent 